\title{
Functional and construction indicator for the briquetting process of lignocellulosic materials
}

\author{
Krzysztof Talaśka ${ }^{1,}{ }^{*}$, Dominik Wojtkowiak ${ }^{1}$, Ireneusz Malujda ${ }^{1}$, Mateusz Kukla ${ }^{1}$ and \\ Krzysztof Wałęsa ${ }^{1}$ \\ ${ }^{1}$ Chair of Basics of Machine Design, Poznan University of Technology, Poznan, 60-965, Poland
}

\begin{abstract}
The study presents the possibility to measure the torque and axial force of the working system of the screw compactor machine with open working chamber. Attention was drawn to the relationship between the two parameters and the geometric properties of the working system and the thermomechanical properties of the compacted materials. A functional construction coefficient was proposed and defined to bound together the value of torque and axial force. Its usability was demonstrated for identifying the parameters of compaction process together with its applicability for controlling these types of processes.
\end{abstract}

Keywords: worm/screw-based compaction machine, lignocellulosic materials

\section{Introduction}

The manufacturing of renewable solid fuel utilizing broken down lignocellulosic materials has been growing in popularity. This is caused by the ecological factors as well as the pressure to reduce the use of fossil fuels and to utilize agricultural waste products. Some countries have a very high overproduction of such materials. This is related to the necessity to cultivate grains. The leftover straw after harvest can be utilized in a number of ways. These include utilizing the straw as bedding, fodder, can be buried in the soil as green manure for additional fertilization. A significant share of utilization of the straw material involves bedding for mycelium. As it turns out, despite intensive utilization of straw, in many countries (also in Poland) there is an overproduction of this material. Table 1 presents the balance of total production and utilization of straw in Poland in the years 2010-2014 as well as the proposed forecast of its utilization by the year 2030 .

Powders and shredded materials need to be compacted to give them the appropriate geometrical form and mechanical properties [9-15]. The manufacturing of renewable solid fuel from broken down lignocellulosic materials requires proper preconditioning of the material, breaking it down, drying and mixing. Afterwards, machines utilizing different compaction techniques are employed to agglomerate the material to achieve the assumed final geometric form. We can identify three basic techniques for compaction: the utilization of a working system based on a piston performing a reciprocating motion within the forming

${ }^{*}$ Corresponding author: krzysztof.talaska@put.poznan.pl

Reviewers: Grzegorz Domek, Andrzej Kołodziej 
sleeve, the utilization of a working system based on worm screw performing a rotating motion within the forming sleeve and a working system based on rollers pressing on forming dies with multiple openings.

Table 1. The balance of the total production and utilization of straw in the years 2010-2030 [1-8]

\begin{tabular}{|c|c|c|c|c|c|c|c|}
\hline & \multicolumn{7}{|c|}{ Year } \\
\hline & \multirow{2}{*}{2010} & \multirow{2}{*}{2011} & \multirow{2}{*}{2012} & \multirow{2}{*}{2013} & \multirow{2}{*}{2014} & \multicolumn{2}{|c|}{ Forecast } \\
\hline & & & & & & 2020 & 2030 \\
\hline $\begin{array}{l}\text { Production } \\
\text { tons] }\end{array}$ & & 28.89 & 30.793 & 29.343 & 35.608 & 30.533 & 30.862 \\
\hline \multicolumn{8}{|l|}{ Utilization [million tons] } \\
\hline Mulch & 11.843 & 11.24 & 10.698 & 10.303 & 10.47 & 9.868 & 9.319 \\
\hline Fodder & 3.923 & 3.914 & 3.898 & 3.763 & 3.806 & 3.527 & 3.221 \\
\hline Green manure & 3 & 3 & 3 & 3 & 3 & 3 & 3 \\
\hline Bedding for mycelium & 1 & 1 & 1 & 1 & 1 & 1 & 1 \\
\hline Balance & 9.987 & 9.736 & 12.198 & 11.277 & 17.322 & 13.138 & 14.322 \\
\hline
\end{tabular}

With machines utilizing the piston technique, it is possible to achieve cylindrical or polygonal (in transverse cross-section) agglomerate with diameter of several dozen millimeters. The roller technique is used to form pellets with several or dozen or so millimeters. On the other hand, the screw-based technique of compaction achieves cylindrical agglomerate with several dozen millimeters with an orifice in the middle. The orifice along the axis of the agglomerate facilitates the removal of steam generated as the compacted material is heated up.

The compacted material is characterized by the defined parameters of fragmentation and moisture. The largest range of allowed moisture in the compacted material still allowing for proper performance of the compaction process is achieved in worm/screw-based machines. Fig. 1 presents a diagram of such a machine.

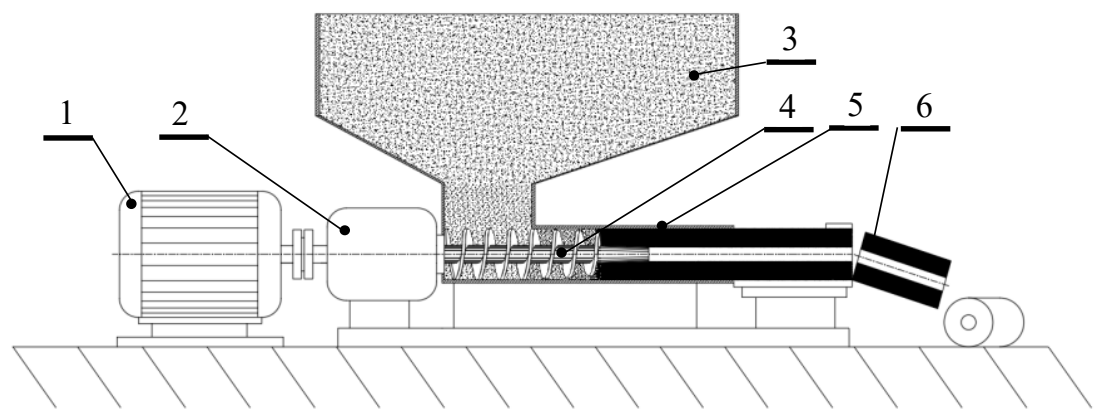

Fig. 1. Worm/screw-based compaction machine with open forming sleeve used in the manufacturing of briquette from broken down lignocellulosic materials: 1 - drive motor, 2 - mechanical transmission, 3 - compacted material, 4 - worm, 5 - heated forming (compacting) sleeve, 6 - final geometric form of the agglomerate

\section{Process parameters for the compaction of lignocellulosic materials utilizing compacting screw technique}

The drive system of the compaction machine utilizing the screw technique can be characterized by two basic usable parameters. These parameters are the torque $T_{r}$ driving the worm and the axial force $F_{a}$ exerted on the worm resultant from axial resistance from the 
displacement of the compressed material. Fig. 2 presents the breakdown of the main geometric parameters of the working system of the compacting machine.

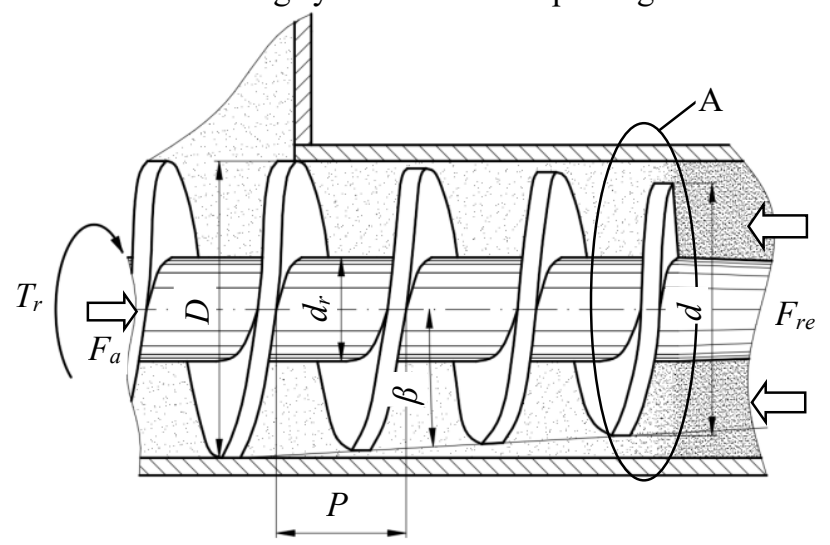

Fig. 2. Geometric properties of the working system of the compaction machine for broken down lignocellulosic materials (compacting screw technique): $D$ - diameter of the cylindrical part of the worm, $d$ - diameter of the working worm twist, $d_{r}$ - worm hub diameter, $\beta$-worm convergence angle, $P$ - worm pitch, $F_{r e}$ - resistance force, $F_{a}$ - axial force, $T_{r}$ - torque, A - main compaction area of the material

The final section of the worm serves as the last stage of compaction between its outside surface and the front side of the compacted material. Therefore, the axial force $F_{a}$ will be equal to resistance force $F_{r e}$. Analyzing the mechanics of the material compaction process within the worm working unit, one needs to conclude that torque is closely related with axial force. Based on this assumption, it is possible to propose a functional-construction indicator $I_{G-F}$ which can be calculated from the following formula:

$$
I_{G-F}=\frac{T_{r}}{F_{a}}
$$

It is predicted that for a given working system (accounting for its geometric properties) the value of this indicator should be approximately equal to a specific value.

In order to determine the value of the indicator $I_{G-F}$, the screw compaction machine was fitted with a torque meter DFM40 and a hydraulic force gauge as described in patent [16]. Fig. 3 presents the diagram of the solution employed for the hydraulic force gauge. Its principle of operation is based on indirect determination of the axial force value through measuring the pressure in the hydraulic chamber between items no. 2, 3, 4. Prior to use, it requires calibration in order to determine the characteristic of change of the axial force as a function of pressure value within the hydraulic chamber. 


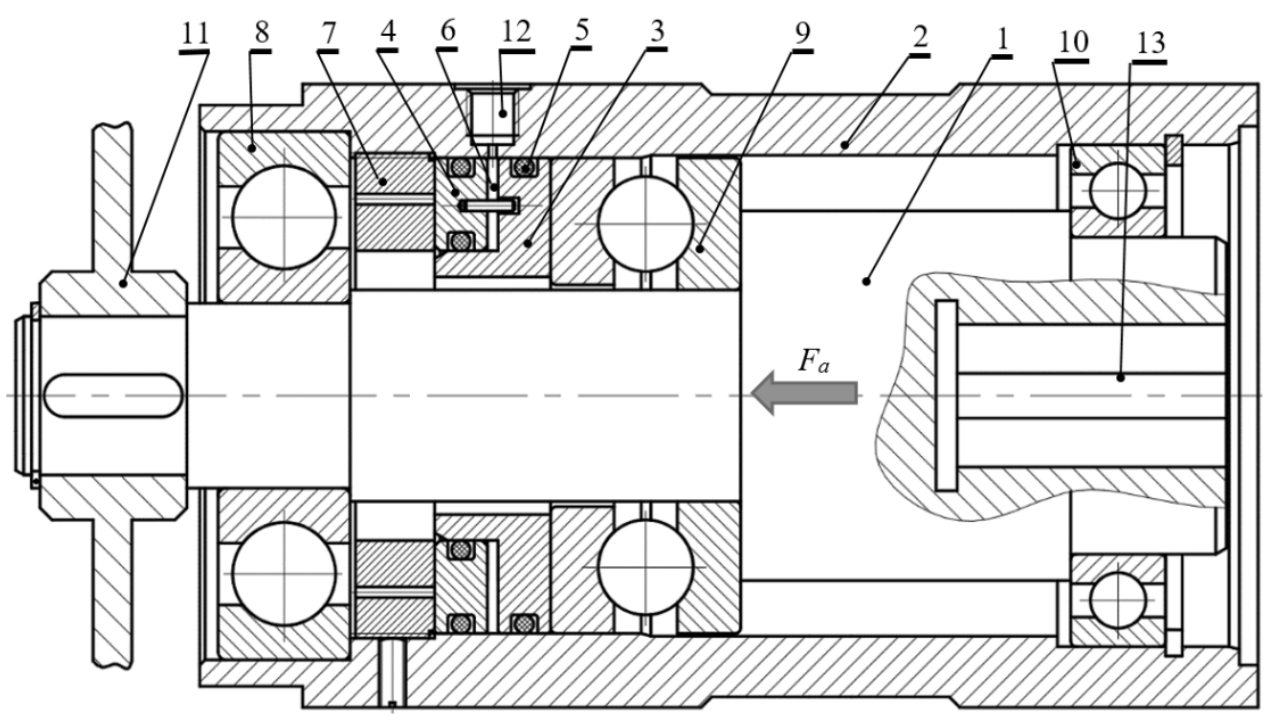

Fig. 3. Hydraulic rotational force gauge: 1 - shaft, 2 - body, 3 - force gauge body 1 , 4 - force gauge body 2, 5 - sealing ring, 6 - pressure chamber, 7 - threaded sleeve, $8,9,10$ - bearing, 11 - chain wheels, 12 - slot for pressure gauge, 13 - slot with inlet groove for the installation of worm pin, $F_{a}-$ axial force $[8,16]$

\section{Methodology and scope of test measurements}

The examination was carried out on a screw compaction machine fitted with a torque meter and a hydraulic force gauge. The compaction process was undertaken for oat straw, rye straw and hay (Fig. 4). The examination was performed at three values of worm rotation speed: 210, 280 and $350 \mathrm{rpm}$. Figs. 5-10 present example results of the examination of axial force and torque together with the value of the indicator $I_{G-F}$ for all materials and worm rotation speed equal to $280 \mathrm{rpm}$. Table 2 presents a breakdown of collected average values of the indicator $I_{G-F}$ for the three materials as well as the three rotation speed values of the worm.

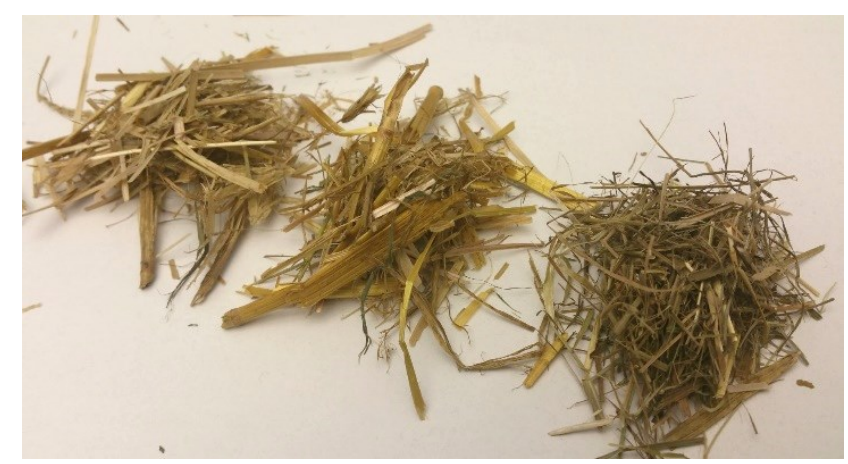

Fig. 4. Materials used for the examination: oat straw, rye straw, hay 


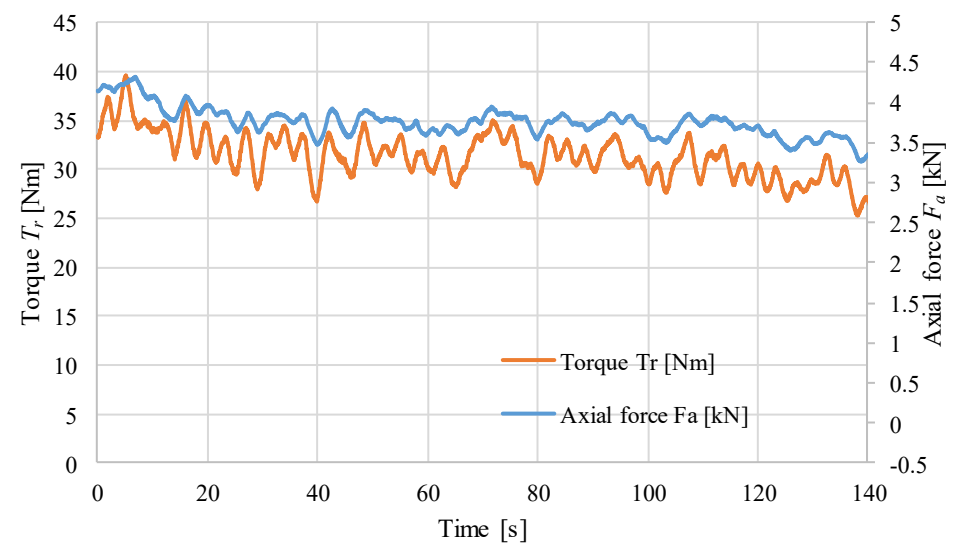

Fig. 5. The change of torque $T_{r}$ and axial force $F_{a}$ as a function of time; rye straw, worm rotation speed $280 \mathrm{rpm}$

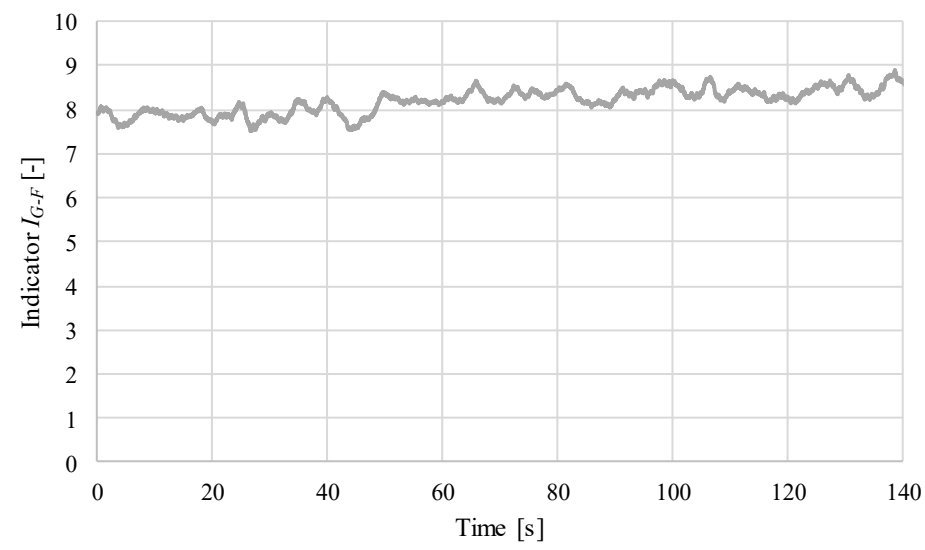

Fig. 6. The change of the functional and construction indicator value $I_{G-F}$ as a function of time; rye straw, worm rotation speed $280 \mathrm{rpm}$

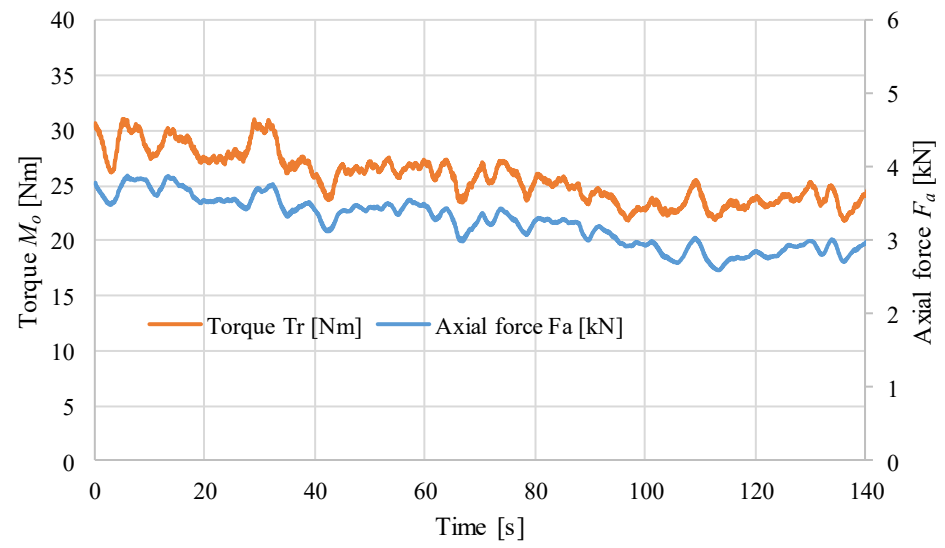

Fig. 7. The change of torque $T_{r}$ and axial force $F_{a}$ as a function of time; oat straw, worm rotation speed $280 \mathrm{rpm}$ 


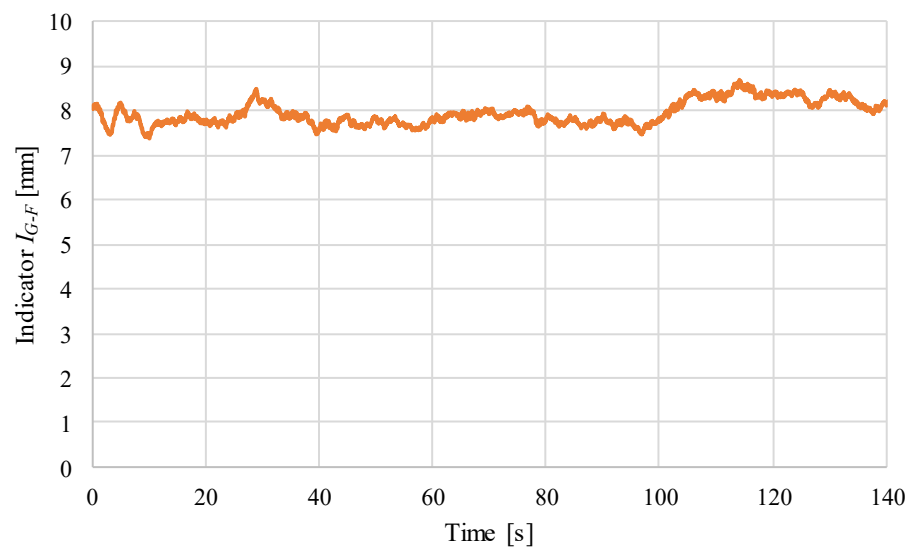

Fig. 8. The change of the functional and construction indicator value $I_{G-F}$ as a function of time; oat straw, worm rotation speed $280 \mathrm{rpm}$

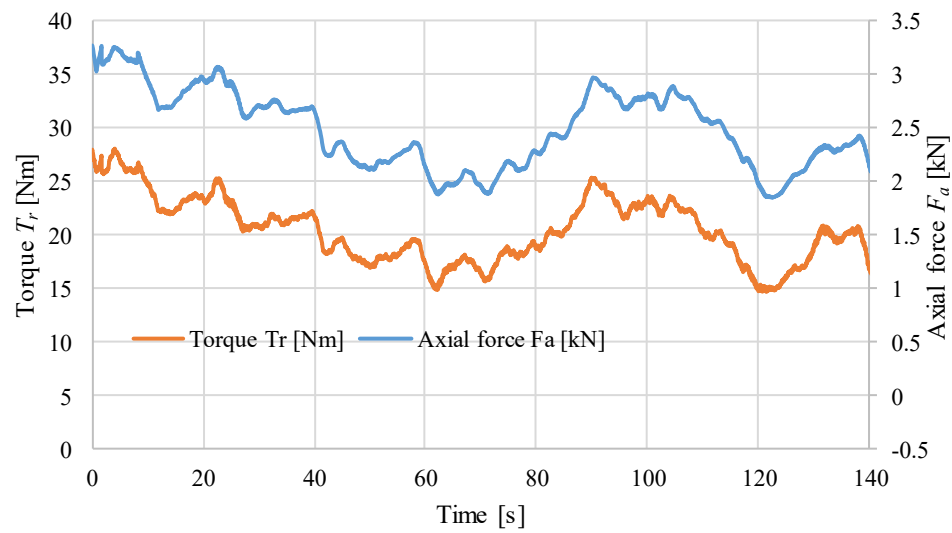

Fig. 9. The change of torque $T_{r}$ and axial force $F_{a}$ as a function of time; hay, worm rotation speed 280 rpm

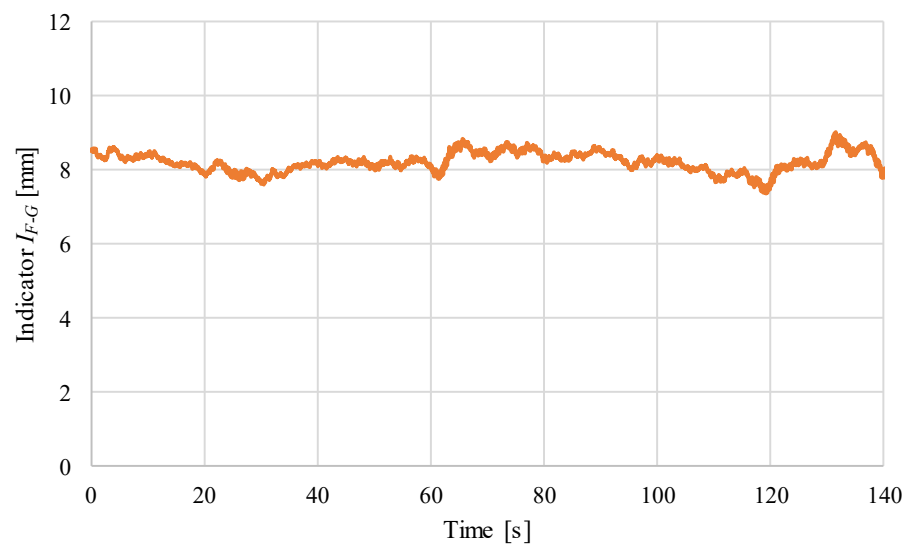

Fig. 10. The change of the functional and construction indicator value $I_{G-F}$ as a function of time; hay, worm rotation speed $280 \mathrm{rpm}$ 
Table 2. Breakdown of the average values of the geometric and functional indicator $I_{G-F}$

\begin{tabular}{|l|c|c|c|}
\hline \multirow{2}{*}{ Material } & \multicolumn{3}{|c|}{ Indicator $I_{G-F}[\mathrm{~mm}]$} \\
\cline { 2 - 4 } & $n_{s 1}$ & $n_{s 2}$ & $n_{s 3}$ \\
\hline Rye straw & 7.93 & 8.34 & 8.29 \\
\hline Oat straw & 7.76 & 8.03 & 7.98 \\
\hline Hay & 7.91 & 8.15 & 8.18 \\
\hline
\end{tabular}

\section{Conclusion}

The proposed functional and construction indicator may be used as a basis for designing control algorithms for screw compaction machines. Additionally, if its value is established, we only need to measure the value of one parameter to estimate the value of the other one. Variable thermomechanical parameters of the broken down lignocellulosic materials influence the ambiguous and unpredictable course of the compaction process. This prevents the design of effective and dedicated working system for selected material. It is therefore more advantageous to monitor the compaction process during its course. This on the other hand calls for specialized control and measuring system assemblies. The construction solutions for the force gauge presented in this paper together with the methodology of monitoring of the compaction process utilizing the functional and construction indicator may benefit the development of adaptive control systems of such machines.

\section{References}

1. GUS: Characteristics of farms in 2013 (in Polish), Warszawa (2014)

2. GUS: Production of agricultural and horticultural crops in 2014 (in Polish), Warszawa (2015)

3. GUS: Land and sown area use in 2014 (in Polish), Warszawa (2015)

4. GUS: Livestock in 2014 (in Polish), Warszawa (2015)

5. A. Faber, J. Kuś, Alternative directions of production of Polish agriculture (in Polish), Pamiętnik Puławski, 132, pp. 59-73 (2003)

6. Cz. Maćkowiak, Straw as a fertilizer on a farm without inventory (in Polish), Wieś Jutra, 5, pp. 46-48 (1998)

7. A. Madej, Straw balance in Poland in 2010-2014 and forecast by 2030 (in Polish), Stowarzyszenie Ekonomistów Rolnictwa i Agrobiznesu, Roczniki Naukowe, t. XVIII, z. 1, pp. 163-168 (2016)

8. K. Talaśka, Study of research and modelling of compaction processes of powder and shredded materials (in Polish), Wydawnictwo Politechniki Poznańskiej, Poznań (2018)

9. K. Talaśka, I. Malujda, D. Wilczyński, Agglomeration of natural fibrous materials in perpetual screw technique - a challenge for designer, Procedia Engineering, 136, pp. 63-69 (2016).

10. D. Wilczyński, K. Talaśka, I. Malujda, R. Długi, The Study of Mechanical Properties of Natural Polymers in the Compacting Process, Procedia Engineering, 177, pp. 411-418 (2017)

11. I. Malujda, D. Wilczyński, Mechanical Properties Investigation of Natural Polymers, Procedia Engineering, 136, pp. 263-268 (2016)

12. D. Wilczyński, K. Talaśka, I. Malujda, P. Jankowiak, Experimental research on biomass cutting process, MATEC Web of Conferences, 157, Article Number 07016 (2018) 
13. J. Górecki, I. Malujda, K. Talaśka, M. Kukla, P. Tarkowski, Influence of the compression length on the ultimate stress in the process of mechanical agglomeration of dry ice, Procedia Engineering, 177, pp. 363-368 (2017)

14. J. Górecki, I. Malujda, K. Talaśka, P. Tarkowski, M. Kukla, Influence of the value of limit densification stress on the quality of the pellets during the agglomeration process of $\mathrm{CO}_{2}$, Procedia Engineering, 136, pp. 269-274 (2016)

15. J. Górecki, I. Malujda, K. Talaśka, D. Wojtkowiak, Dry ice compaction in piston extrusion process, Acta mechanica et automatica, 11, pp. 313-316 (2017)

16. J. Płotkowiak, J. Adamiec, M. Dudziak, I. Malujda, K. Talaśka, Hydrauliczny siłomierz obrotowy, Polish patent no. 225645, Warszawa (2017) 